\title{
THE EFFECT OF BLOCK AND TRADITIONAL PERIODIZATION MODELS ON JUMPING AND SPRINTING DYNAMICS DURING THE SIMULATED BASKETBALL GAMES
}

\author{
Vytautas Pliauga ${ }^{1,2}$, Inga Lukonaitiené ${ }^{1}$, Kristina Bradauskiené $\dot{e}^{1}$, Irina Kliziené2 \\ Daniele Conte ${ }^{1}$, Jūratė Stanislovaitiené ${ }^{1}$ \\ Lithuanian Sports University', Kaunas, Lithuania \\ Kaunas University of Technology,2, Kaunas, Lithuania
}

\begin{abstract}
Background. The aim of the study was to compare the effect of block and traditional periodization preseason preparation on advanced players' jumping and sprinting dynamics during the simulated basketball games.

Methods. Ten college-level males (age (mean \pm standard deviation (SD)), $21.5 \pm 1.7$ years; weight, $83.5 \pm$ $8.9 \mathrm{~kg}$; height, $192.5 \pm 5.4 \mathrm{~cm}$ ) were divided into two teams according to the training model: block periodization (BP) and traditional periodization (TP). Block periodization (BP) consisted of the following blocks: aerobic endurance $(\mathrm{AE})$, power endurance (PE), basketball specific aerobic endurance (BSAE), and power (P). Both groups played a simulated basketball game with each other before and after preseason preparation. Vertical countermovement jump and 20 meters sprint were measured before each simulated game and after each quarter of the game.

Results. In BP, the 8 weeks of preseason training resulted in elevated vertical jump and 20 meters sprint dynamics during simulated games $(p<.05)$.

Conclusion. We conclude that 8 weeks of block periodization enhanced leg power production and sprint abilities during simulated games and therefore is more effective than traditional periodization model.
\end{abstract}

Keywords: basketball, power, periodization.

\section{INTRODUCTION}

$\mathrm{C}$ oaches search for training methods which might imitate the real match demands, aiming to develop both sport-specific skills and improving physical fitness performance (Marcelino et al., 2016). In basketball, it is particularly important to have highly developed power capabilities because this sport includes high-intensity game elements, such as changes of direction, dribble, sprints, jumps, shots, and passes (Abdelkrim et al., 2010; Conte et al., 2015; Scanlan at al., 2012). The external load of players per game consists of up to 1,000 different actions (Conte et al., 2015; Conte, Tessitore, Smiley, Thomas, \& Favero, 2016; Scanlan et al., 2012), including about 45 jumps, whereas movement sequences are performed in an intermittent fashion and seldom last for longer than $20 \mathrm{~s}$ (Conte at al., 2016). Because of this, basketball training requires understanding of the demands of the game and methodological approach is essential for combining all subcomponents of the basketball-training program.

The traditional approach of designing training plans of traditional development of different physical abilities at the same time is still widely used (Issurin, 2016). In contrast, the block periodization training employs highly focused training workloads on particular physical ability for approximately 3-6 weeks (Issurin, 2016). Some studies have reported superior strength, power, and local muscular endurance gains using traditional 
periodization (Monteiro et al., 2009; Rhea, Ball, Phillips, \& Burkett, 2002), whereas other studies have shown no significant differences in these strategies or have favoured block periodization (Bartolomei, Hoffman, Merni, \& Stout, 2014; Buford, Rossi, Smith, \& Warren, 2007; GarcíaPallarés, García-Fernández, Sánchez-Medina, \& Izquierdo, 2010; Hartmann, Bob, Wirth, \& Schmidtbleicher, 2009; Hoffman et al., 2009). It should be noted that the majority of studies used strength training programs that compared the two periodization models. Hence, the training process in team sports is more complex compared with individual strength training, as preseason conditioning activities should replicate game situations to ensure that players are prepared appropriately for competition.

When coaches design training plans, they have limited time to provide training only for power enhancement; therefore, they combine power exercises with specific basketball drills by alternating exercise intensity and duration. The effect of such training strategies on athletes' physical abilities is poorly understood. It is unclear how combined training translates into actual power production in players. Therefore, the current study aimed to compare the effects of basketball specific block and traditional periodization models on advanced players' jumping and sprinting dynamics during the simulated games. Taking into consideration the greater concentration of loads, it was expected that by applying block periodization, athletes would achieve higher results in both vertical jump and 20 meters sprint dynamics during simulated games.

\section{METHODS}

Subjects. Ten ( 6 frontcourt and 4 backcourt) college-level male basketball players (mean \pm $S D$; age: $21.5 \pm 1.7 \mathrm{y}$-o; body mass: $83.5 \pm 8.9 \mathrm{~kg}$; stature: $192.5 \pm 5.4 \mathrm{~cm}$; training experience: $7.6 \pm$ 1.1 years) belonging to the same team voluntarily participated in this study. Participants were free of injuries in the 6 months before the start of the study. The experiment was performed during the preseason period, during which players trained 1-2 h per day and 5-6 days per week. Players did not undertake intensive exercise in the $48 \mathrm{~h}$ before each testing procedure. All players were notified about the aim of the study, research procedures, requirements, benefits, and all participants and parents gave informed consent. Ethics approval was granted from the Kaunas Regional Ethical Committee Review Board.

Procedure. This is an intervention study and data were gathered before and after the 8-week preseason preparation. Participants were equally divided in two training groups according to the two analysed training periodization models: block periodization (BP) and traditional periodization (TP). Players within each group were matched by the coaching staff according to their skill levels and on-court positions. The principal loading scheme of different periodization models is presented in Table 1. The BP model consisted of the four blocks (aerobic endurance, power endurance, basketball specific aerobic endurance, and power) with 2-week duration each (Table 2).

In the TP model, similar training stimuli were combined within each microcycle as shown in Table 3. In both TP and BP, similar exercise intensity and volume were administered in the 8 analysed weeks. Moreover, training stimuli were mainly characterized by the same basketball-specific technical and tactical drills except for the first block in the BP model (aerobic endurance) in which players were only involved in jogging and running activities. Each training session was preceded by $20-25 \mathrm{~min}$ standardized warm-up including jogging, dynamic stretching, and basketballspecific drills (i.e. ball-handling, shooting and free throws) and followed by 15 to $20-$ min cool down in which core conditioning exercises and static stretching were performed.

In this study, the training periodization model was the independent variables, while vertical jump height and sprint dynamics during the simulated basketball game were used as dependent variables. Each participant completed two testing sessions: before intervention (baseline) and after 8 weeks of preseason preparation. In the first testing session, the body height and mass were measured and then the subjects completed a standardized questionnaire indicating their age and training experience. Afterwards, the two teams played a simulated game following a standardized warmup consisting of 7-min jogging, 5-min dynamic stretching, and 10-min low-intensity basketballspecific drills. 20 meter sprint and vertical countermovement jump tests were performed before and after the warmup and immediately after each of the four quarters of the simulated games. 
Table 1. Principal loading scheme of different periodization models

\begin{tabular}{|c|c|c|c|c|c|c|c|c|c|c|c|}
\hline \multicolumn{8}{|c|}{$1^{\text {st }}$ Microcycle (week 1-2) (same load for both weeks) } & \multicolumn{4}{|c|}{ Total } \\
\hline & Mon & Tues & Wed & Thurs & Fri & Sat & Sun & A & $\mathrm{P}$ & $\mathrm{PE}$ & $\mathrm{R}$ \\
\hline BP & A & A & A & A & A & $\mathrm{R}$ & $\mathrm{R}$ & 10 & - & - & 4 \\
\hline $\mathbf{T P}$ & $\mathrm{P}$ & PE & A & $\mathrm{P}$ & $\mathrm{PE}$ & A & $\mathrm{R}$ & 4 & 4 & 4 & 4 \\
\hline \multicolumn{8}{|c|}{$2^{\text {nd }}$ Microcycle (week 3-4) (same load for both weeks) } & \multicolumn{4}{|c|}{ Total } \\
\hline BP & PE & PE & A & PE & $\mathrm{PE}$ & A & $\mathrm{R}$ & 4 & - & 8 & 2 \\
\hline $\mathbf{T P}$ & $\mathrm{P}$ & PE & A & $\mathrm{P}$ & $\mathrm{PE}$ & A & $\mathrm{R}$ & 4 & 4 & 4 & 4 \\
\hline \multicolumn{8}{|c|}{$3^{\text {rd }}$ Microcycle (week 5-6) (same load for both weeks) } & \multicolumn{4}{|c|}{ Total } \\
\hline BP & A & A & A & A & A & $\mathrm{R}$ & $\mathrm{R}$ & 10 & - & - & 4 \\
\hline TP & $\mathrm{P}$ & $\mathrm{PE}$ & A & $\mathrm{P}$ & $\mathrm{PE}$ & A & $\mathrm{R}$ & 4 & 4 & 4 & 4 \\
\hline \multicolumn{8}{|c|}{$4^{\text {th }}$ Microcycle (week 7-8) (same load for both weeks) } & \multicolumn{4}{|c|}{ Total } \\
\hline BP & $\mathrm{P}$ & $\mathrm{P}$ & A & $\mathrm{P}$ & $\mathrm{P}$ & $\mathrm{R}$ & $\mathrm{R}$ & 2 & 8 & - & 4 \\
\hline TB & $\mathrm{P}$ & $\mathrm{PE}$ & A & $\mathrm{P}$ & $\mathrm{PE}$ & A & $\mathrm{R}$ & 4 & 4 & 4 & 4 \\
\hline
\end{tabular}

Note. $\mathrm{TP}$ - traditional periodization, $\mathrm{BP}$ - block periodization, $\mathrm{A}$ - aerobic endurance, $\mathrm{P}$ - power, $\mathrm{PE}$ - power endurance, $\mathrm{R}$ - rest.

Table 2. Block periodization scheme

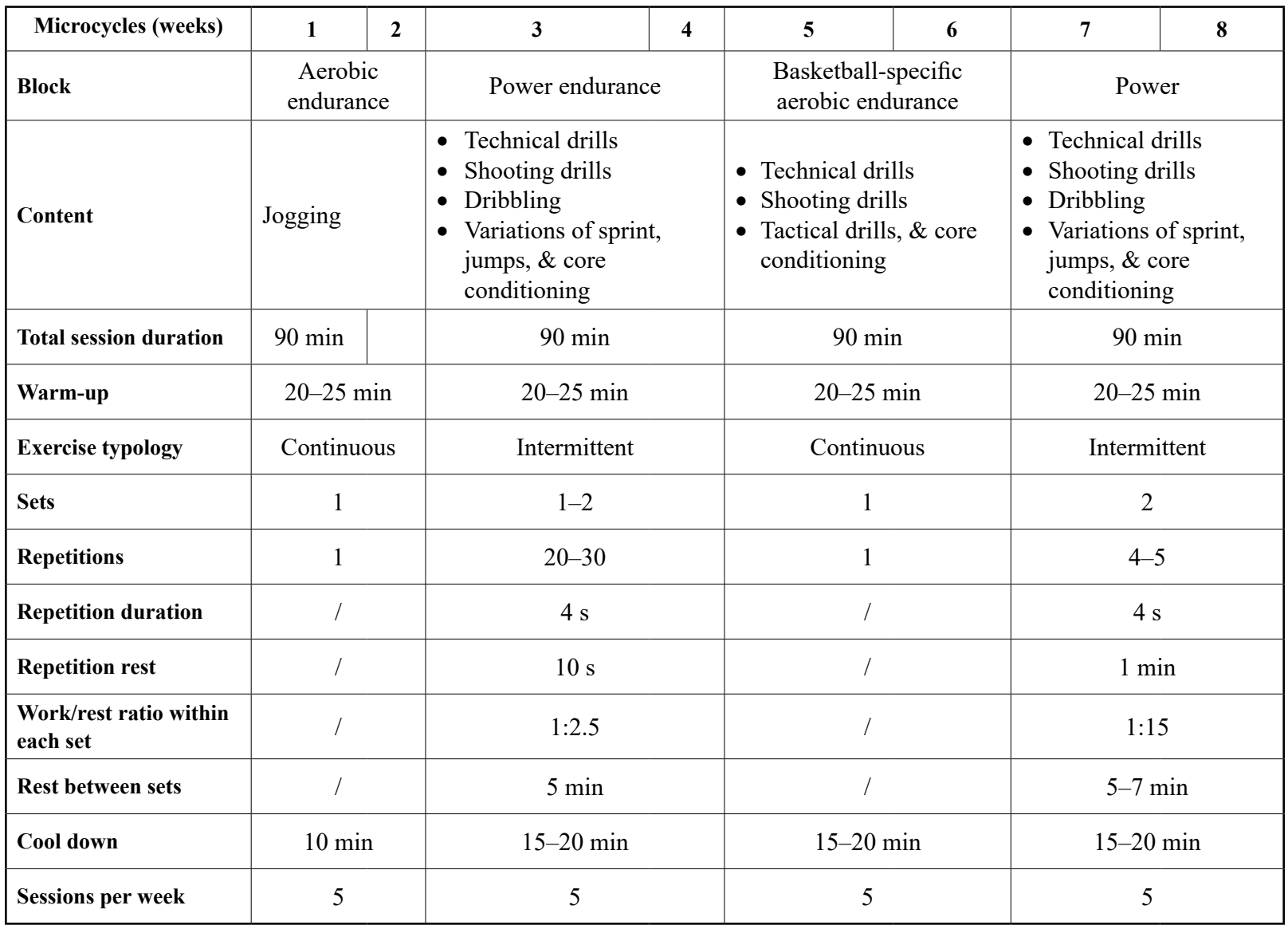


Table 3. Traditional periodization microcycle

\begin{tabular}{|c|c|c|c|}
\hline Week days & Days 1 and 4 & Days 2 and 5 & Day 3 and 6 \\
\hline Training session & Power & Power endurance & $\begin{array}{l}\text { Basketball-specific aerobic } \\
\text { endurance }\end{array}$ \\
\hline Contents & $\begin{array}{l}\text { - Technical drills } \\
\text { - Shooting drills } \\
\text { - Dribbling } \\
\text { - Variations of sprint, jumps, } \\
\text { \& core conditioning }\end{array}$ & $\begin{array}{l}\text { - Technical drills } \\
\text { - Shooting drills } \\
\text { - Dribbling } \\
\text { - Variations of sprint, jumps, } \\
\text { \& core conditioning }\end{array}$ & $\begin{array}{l}\text { - Technical drills } \\
\text { - Shooting drills } \\
\text { - Tactical drills, \& core } \\
\text { conditioning }\end{array}$ \\
\hline Total session duration & $90 \mathrm{~min}$ & $90 \mathrm{~min}$ & $90 \mathrm{~min}$ \\
\hline Warm-up & $20-25 \mathrm{~min}$ & $20-25 \mathrm{~min}$ & $20-25 \mathrm{~min}$ \\
\hline Exercise typology & Intermittent & Intermittent & Continuous \\
\hline Sets & 2 & $1-2$ & 1 \\
\hline Repetitions & $4-5$ & $20-30$ & 1 \\
\hline Repetition duration & $4 \mathrm{~s}$ & $4 \mathrm{~s}$ & / \\
\hline Repetition rest & $1 \mathrm{~min}$ & $10 \mathrm{~s}$ & / \\
\hline Work/rest ratio within each set & $1: 15$ & $1: 2.5$ & / \\
\hline Rest between sets & $5-7 \mathrm{~min}$ & $5 \mathrm{~min}$ & / \\
\hline Cool down & $15-20 \mathrm{~min}$ & $15-20 \mathrm{~min}$ & $15-20 \mathrm{~min}$ \\
\hline Sessions per week & 2 & 2 & 2 \\
\hline
\end{tabular}

Counter-movement jump (CMJ) with arm swing. This test had been previously used in basketball to assess vertical jump performance (Boccolini, Brazzit, Bonfanti, \& Alberti, 2013; Nikolaidis, Calleja-González, \& Padulo, 2014). Participants performed the vertical jump on a contact mat (Powertimer Testing System, New Test, Oulu, Finland) starting from an upright standing position with preliminary downward movement to a knee angle of approximately $90^{\circ}$ with an arm swing. Three trials were performed with $20 \mathrm{~s}$ of rest between each trial. The best result was used for analysis. If the third trial result was the best, one additional trial was carried out (Pliauga et al., 2015). The height of the jumps was calculated by applying the following equation: $\mathrm{H}=1.226 \times \mathrm{Tf} 2(\mathrm{~m})$, where $\mathrm{Tf}=$ flight time (s) (Bosco, Viitasalo, Komi, \& Luhtanen., 1982). The best result was used for further analysis. The ICC for this test was established previously $(0.95$ (Kamandulis et al., 2013)).

20-meter sprint test, which had been widely used previously (Kamandulis et al., 2013; Pliauga et al., 2015). Running time was recorded using the Power time Testing System (New Test, Oulu, Finland). Photo-sensing elements connected to an electronic chronometer were placed $20 \mathrm{~m}$ apart. The starting position was $70 \mathrm{~cm}$ from the first photosensing element. Two trials were conducted with a recovery time of approximately 2 min between them. The best result was used for analysis. The intra-class correlation coefficient (ICC) for this test was established previously (0.95) (Kamandulis et al., 2013).

Simulated basketball game. The participants were then divided into two teams by the coach. The criteria for team assignment were the basketball performance level and playing position. The two teams played a simulated game that consisted of four 10 min quarters with a 15 min break at half time and 8-min breaks after the first and the third quarters. The players usually had a 2 min break for rest after the first and the third quarters, but the subjects in the present study rested for $2 \mathrm{~min}$ during those breaks and then performed tests for $6 \mathrm{~min}$. The game involved official umpires, and took place on an indoor basketball court. Player substitutions were not allowed, and the players stayed in the game even when they had five fouls. This protocol of simulated basketball game was established previously (Pliauga et al., 2015).

Statistical Analysis. Descriptive data are presented as the mean $\pm \mathrm{SD}$. A nonparametric 
Mann-Whitney test was used to compare differences in jump height and 20 meters sprint results between the control and experimental groups. Jump height and 20 meters sprint speed comparison within groups was performed using a nonparametric Wilcoxon test. The level of significance was set at .05. All analyses were performed using SPSS (SPSS, Inc., Version 20.0, Chicago, IL).

\section{RESULTS}

The height of vertical jumps before and after preseason preparation in $\mathrm{BP}$ and $\mathrm{TP}$ is presented in Figure 1. No differences were found between the
$\mathrm{BP}$ and TP before the preseason preparation. The BP group exhibited major increases in jump height dynamics during the simulated games $(p<.05)$. In contrast, there was no increase in jump height in the TP group at any time point of simulated basketball games.

The changes in 20 meters sprint are presented in Figure 2. BP and TP groups before the preseason preparation did not differ. After the preparation the BP group increased 20 meter sprint results during the simulated games with significant differences after second, third and fourth quarters $(p<.05)$. However, there were no significant increases in TP group.
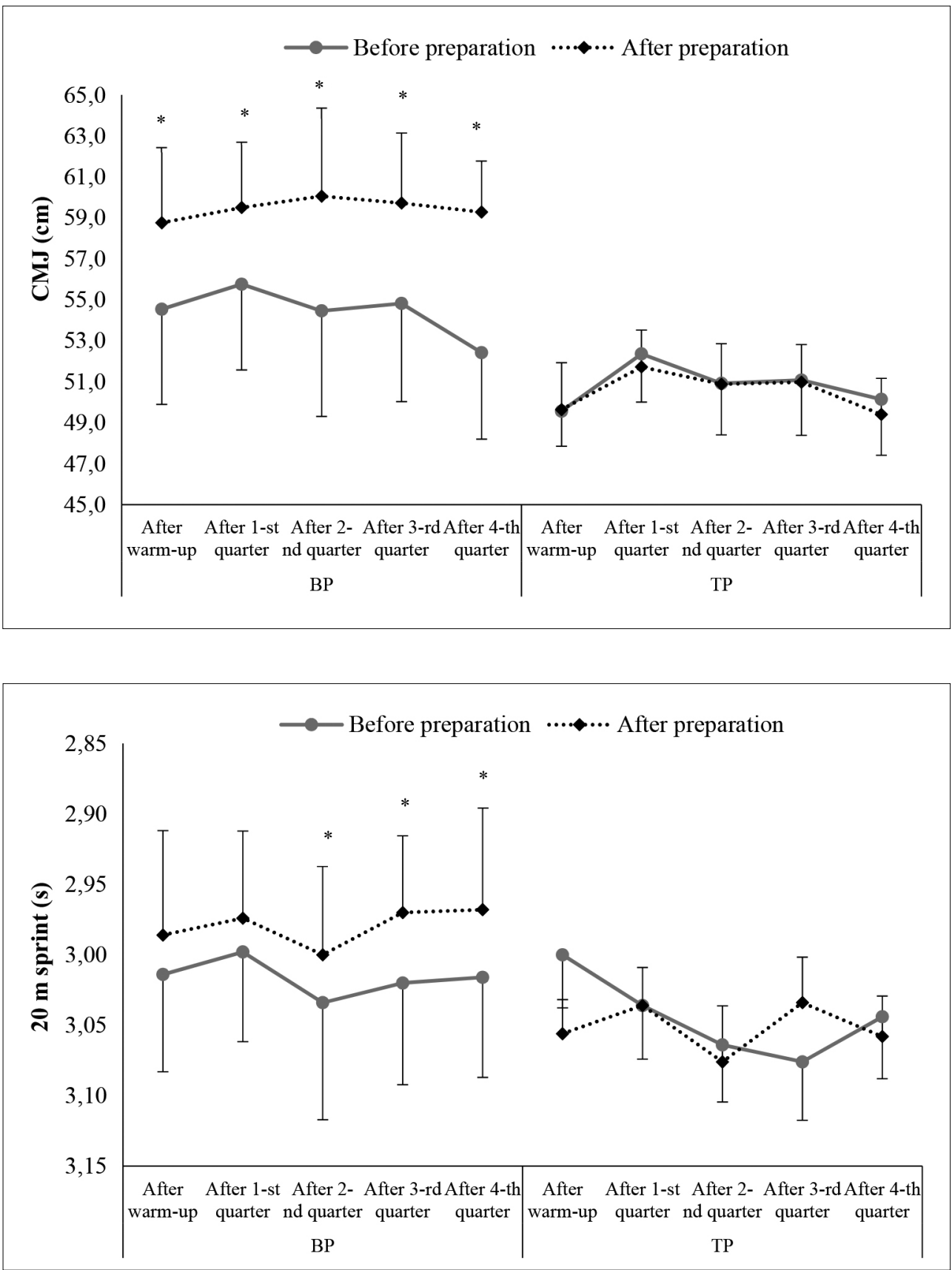

Figure 1. Mean ( \pm SD) values of vertical jump height during the simulated basketball games in block periodization (BP) and traditional periodization (TP) groups

Note. * - significantly different compared to before preparation.

Figure 2. Mean ( \pm SD) values of 20 meter sprint during the simulated basketball games

Note. $*$ - significantly different compared to before preparation. 


\section{DISCUSSION}

The aim of the study was to compare the effect of block and traditional periodization preseason preparation on advanced players' jumping and sprinting dynamics during the simulated basketball games. The training time to prepare basketball team is limited and in short duration of preparation coaches tend to cover many aspects of the game and conditioning, e.g. tactical preparation, defensive and offensive drills, shooting, endurance training and power. With that in mind, by using specific basketball drills and variations of work-rest ratio and intensity we expected not only developed the players' physical condition but also improved their game related skills. We confirmed that short concentrated training loads with a gradual increase in intensity (BP) tended to improve athletes' jumping and sprinting performance during the simulated basketball games. Block loading strategy appeared to have advantage over traditional periodization.

Different periodization approaches to improve athletes' anaerobic capacity have been studied previously (Bartolomei et al., 2014; García-Pallarés et al., 2010; Hartmann et al., 2009; Marques, Franchini, Drago, Aoki, \& Moreira, 2017). One investigation analysing the effect of 15 weeks of BP and TP training structured with an equal volume of anaerobic exercises indicated an improvement of upper body power in BP compared to TP in power athletes, while no substantial changes were noted between groups in lower body strength and jump performances (Bartolomei et al., 2014). Conversely, in the current investigation a substantial improvement in CMJ and 20 meters sprint during simulated basketball games was shown following 8-week BP training, while no substantial changes were observed after the TP training. These data suggest that BP can induce performance increases in both 20 meters sprint and in CMJ.

In the TP model proposed by Matveev (1965), macrocycles and mesocycles are arranged for transition from high-volume and low-intensity workloads to high-intensity and low-volume workloads. Moreover, this model is based on the simultaneous development of many fitness components, e.g. aerobic capacity, strength, power, within a regular workload distribution (Matveev, 1965; Issurin, 2008; Issurin, 2016). In our study, the same microcycle was used during the whole preseason preparation and different training stimuli (P, PE, BSAE training sessions) were combined within each microcycle. This loading strategy is still popular among the coaches (Issurin, 2016). However, Kirby, Erickson, \& McBride (2010) suggested that athlete cannot train for different concurrent variables at once optimally. Each variable must be addressed in various training blocks so that the best combination can be obtained and result in success for the athlete (Kirby et al., 2010).

The BP model was constituted by mesocycles with a specific training goal and their progression is performed in logical order aiming to prepare athletes for the subsequent training block (Bondarchuk, 1988; Issurin, 2008, 2016). In our study, 2-week specific blocks were adopted: accumulation (aerobic endurance and power endurance), transformation (basketball specific aerobic endurance) and realization (power). Aerobic endurance training block prepared players for more intensive and challenging power endurance block. It was showed that power endurance training produced significant increases in anaerobic capacity (Balčiūnas, Stonkus, Abrantes, \& Sampaio, 2006). However, vertical jump and $20 \mathrm{~m}$ sprint test did not change after intermittent power endurance training (Balčiūnas et al., 2006). Conversely, in our study the results of CMJ during the simulated games increased significantly during the whole game compared to the first simulated games. This could be due to the use of basketball specific aerobic endurance and power blocks after intermittent power endurance training. Moreover, considering that athletes' performance increased at the end of the preseason period, it seems fundamental the use conjugated sequence model correctly sequenced and integrated.

The major limitation of this study was the low number of players examined. However, we preferred to restrict our investigation to a single basketball team, to avoid complications related to the attitude and training discipline variations of members of other teams.

\section{CONCLUSION}

Eight weeks of block periodization training including specific basketball drills tended to enhance leg power and sprint performance during 
the simulated basketball games. In addition, there was a clear tendency for greater effectiveness of the block periodization compared to traditional periodization strategy that may be meaningful for coaches who aim to combine conditioning and specific basketball exercises in the preseason preparation of players.
Acknowledgements. We express our appreciation to the late Prof. Dr. Aleksas Stanislovaitis, whose ideas and contribution to this work was of greatest significance.

Conflict of interest. The authors declare no conflict of interests regarding the publication of this manuscript.

\section{REFERENCES}

Abdelkrim, N., Castagna, C., Jabri, I., Battikh, T., El Fazaa, S., \& El Ati, J. (2010). Activity profile and physiological requirements of junior elite basketball players in relation to aerobic-anaerobic fitness. Journal of Strength and Conditioning Research, 24(9), 23302342. doi: 10.1519/JSC.0b013e3181e381c1

Balčiūnas, M., Stonkus, S., Abrantes, C., \& Sampaio, J. (2006). Long term effects of different training modalities on power, speed, skill and anaerobic capacity in young male basketball players. Journal of Sports Science \& Medicine, 5(1), 163.

Bartolomei, S., Hoffman, J. R., Merni, F., \& Stout, J. R. (2014). A comparison of traditional and block periodized strength training programs in trained athletes. Journal of Strength and Conditioning Research, 28(4), 990-997. doi: 10.1519/JSC.0000000000000366

Boccolini, G., Brazzit, A., Bonfanti, L., \& Alberti, G. (2013). Using balance training to improve the performance of youth basketball players. Sport Sciences for Health, 9(2), 37-42. https://doi.org/10.1007/s11332013-0143-z

Bondarchuk, A. (1988). Constructing a training system. Track Technique, 102(1), 3254-3259.

Bosco, C., Viitasalo, J., Komi, P., \& Luhtanen, P. (1982). Combined effect of elastic energy and myoelectrical potentiation during stretch-shortening cycle exercise. Acta Physiologica, 114(4), 557-565.

Buford, T. W., Rossi, S. J., Smith, D. B., \& Warren, A. J. (2007). A comparison of periodization models during nine weeks with equated volume and intensity for strength. Journal of Strength and Conditioning Research, 21(4), 1245. https://doi.org/10.1519/R-20446.1

Conte, D., Favero, T. G., Lupo, C., Francioni, F. M., Capranica, L., \& Tessitore, A. (2015). Time-motion analysis of italian elite women's basketball games: Individual and team analyses. Journal of Strength and Conditioning Research, 29(1), 144-150. doi: 10.1519/ JSC.0000000000000633

Conte, D., Tessitore, A., Smiley, K., Thomas, C., \& Favero, T. G. (2016). Performance profile of NCAA division I men's basketball games and training sessions. Biology of Sport, 33(2), 189-194. doi: $10.5604 / 20831862.1200512$
García-Pallarés, J., García-Fernández, M., SánchezMedina, L., \& Izquierdo, M. (2010). Performance changes in world-class kayakers following two different training periodization models. European Journal of Applied Physiology, 110(1), 99-107. doi: 10.1007/ s00421-010-1484-9.

Hartmann, H., Bob, A., Wirth, K., \& Schmidtbleicher, D. (2009). Effects of different periodization models on rate of force development and power ability of the upper extremity. Journal of Strength and Conditioning Research, 23(7), 1921-1932. doi: 10.1519/ JSC.0b013e3181b73c69

Hoffman, J. R., Ratamess, N. A., Klatt, M., Faigenbaum, A. D., Ross, R. E., Tranchina, N. M., \& Kraemer, W. J. (2009). Comparison between different off-season resistance training programs in Division III American College football players. The Journal of Strength \& Conditioning Research, 23(1), 11-19.

Issurin, V. B. (2016). Benefits and limitations of block periodized training approaches to athletes' preparation: A review. Sports Medicine, 46(3), 329-338. doi: 10.1007/ s40279-015-0425-5

Issurin, V. (2008). Block periodization versus traditional training theory: A review. Journal of Sports Medicine and Physical Fitness, 48(1), 65.

Kamandulis, S., Venckūnas, T., Masiulis, N., Matulaitis, K., Balčiūnas, M., Peters, D., \& Skurvydas, A. (2013). Relationship between general and specific coordination in 8-to 17-year-old male basketball players. Perceptual and Motor Skills, 117(3), 821-836. https:// doi.org/10.2466/25.30.PMS.117x28z7

Kirby, T. J., Erickson, T., \& McBride, J. M. (2010). Model for progression of strength, power, and speed training. Strength \& Conditioning Journal, 32(5), 86-90. Marcelino, P. R., Aoki, M. S., Arruda, A., Freitas, C. G., Mendez-Villanueva, A., \& Moreira, A. (2016). Does small-sided-games' court area influence metabolic, perceptual, and physical performance parameters of young elite basketball players? Biology of Sport, 33(1), 37-42. doi: 10.5604/20831862.1180174

Marques, L., Franchini, E., Drago, G., Aoki, M. S., \& Moreira, A. (2017). Physiological and performance changes in national and international judo athletes 
during block periodization training. Biology of Sport, 34(2), 371-378.

Matveev, L. P. (1965). Periodization of athletic training. Moscow: Fizkultura I Sport.

Monteiro, A. G., Aoki, M. S., Evangelista, A. L., Alveno, D. A., Monteiro, G. A., da Cruz Piçarro, I., \& Ugrinowitsch, C. (2009). Nonlinear periodization maximizes strength gains in split resistance training routines. The Journal of Strength \& Conditioning Research, 23(4), 1321-1326. doi: 10.1519/ JSC.0b013e3181a00f96

Nikolaidis, P., Calleja-González, J., \& Padulo, J. (2014). The effect of age on positional differences in anthropometry, body composition, physique and anaerobic power of elite basketball players. Sport Sciences for Health, 10(3), 225-233.
Pliauga, V., Kamandulis, S., Dargevičiūtè, G., Jaszczanin, J., Klizienè, I., Stanislovaitienè, J., \& Stanislovaitis, A. (2015). The effect of a simulated basketball game on players' sprint and jump performance, temperature and muscle damage. Journal of Human Kinetics, 46(1), 167-175.

Rhea, M. R., Ball, S. D., Phillips, W. T., \& Burkett, L. N. (2002). A comparison of linear and daily undulating periodized programs with equated volume and intensity for strength. The Journal of Strength \& Conditioning Research, 16(2), 250-255.

Scanlan, A. T., Dascombe, B. J., Reaburn, P., \& Dalbo, V. J. (2012). The physiological and activity demands experienced by Australian female basketball players during competition. Journal of Science and Medicine in Sport, 15(4), 341-347. doi: 10.1016/j. jsams.2011.12.008 